\title{
Induction of Astrocyte Differentiation by Endothelial Cells
}

\author{
Huaiyu Mi, Henry Haeberle, and Ben A. Barres \\ Stanford University School of Medicine, Department of Neurobiology, Stanford, California 94305-5125
}

\begin{abstract}
Here we have investigated the mechanisms that control astrocyte differentiation within the developing rat optic nerve. Astrocytes are normally generated by astrocyte precursor cells within the embryonic optic nerve. We show that there is a close temporal and spatial correlation between endothelial and astrocyte differentiation. We tested the potential role of endothelial cells in inducing astrocyte differentiation by developing an immunopanning method to highly purify endothelial cells from developing optic nerves. We show that the purified endothelial cells, but not other embryonic optic nerve cell types, strongly induce the differentiation of purified astrocyte precursor cells into astrocytes in vitro. Leukemia inhibitory factor (LIF) and LIF receptors have been implicated previously in astrocyte differentiation in vivo. We show that purified endothelial cells express
\end{abstract}

LIF mRNA and that their ability to induce astrocyte differentiation is prevented by a neutralizing anti-LIF, but not anti-ciliary neurotrophic factor, antiserum. These findings demonstrate a role for endothelial cells in inducing astrocyte differentiation. The induction of astrocyte differentiation by endothelial cells makes sense phylogenetically, anatomically, and functionally, because astrocytes evolved concurrently with brain vasculature and ensheathe capillaries throughout the brain. The ability to purify and culture astrocytes and endothelial cells should provide an excellent model system for future studies of bloodbrain barrier development.

Key words: glial development; vasculature; capillaries; astrocyte precursor cells; leukemia inhibitory factor (LIF); endothelial cells; blood-brain barrier
To better understand the cell-cell interactions that control astrocyte development, we have been focusing on the development of glial cells within the rat optic nerve. The optic nerve is part of central white matter and, in addition to the axons of retinal ganglion cells, contains the same glial cell types found in white matter throughout the CNS. Previous studies have found that two different glial lineages develop within the nerve (Raff et al., 1984; Miller et al., 1985, 1989). Type-1 astrocytes develop in the embryonic optic nerve from astrocyte precursor cells (APCs) (Raff et al., 1984; Miller et al., 1985, 1989; Mi and Barres, 1999), whereas oligodendrocytes develop in the postnatal optic nerve from oligodendrocyte precursor cells (Raff et al., 1983; Miller et al., 1985).

In the developing brain, it has been found previously that astrocytes are generated by neural stem cells located in the ventricular zone and subventricular zone (Levison and Goldman, 1993; Goldman, 1996; Barres, 1999). The generation of astrocytes from multipotent neural stem cells in culture is induced by bone morphogenetic factors, ciliary neurotrophic factor (CNTF), leukemia inhibitory factor (LIF), basic FGF (bFGF), and Notch signaling (Hughes et al., 1988; Lillien et al., 1988; Yoshida et al., 1993; Nakagaito et al., 1995; Gross et al., 1996; Johe et al., 1996; Richards et al., 1996; Bonni et al., 1997; Qian et al., 1997; Nakashima et al., 1999a; Wang and Barres, 2000). There is evidence that precursor cells committed to the astrocyte lineage also exist within the developing brain (Fok-Seang and Miller, 1992; Davis and Temple, 1994; Qian et al., 1998; Mi and Barres,

Received Oct. 5, 2000; revised Dec. 6, 2000; accepted Dec. 19, 2000.

This work was supported by National Eye Institute Grant EY10257 (to B.A.B.). We thank Story Landis for the LIF-deficient optic nerves and Peter Newman for the mouse anti-rat PECAM-1 antibody.

Correspondence should be address to Ben A. Barres, Stanford University School of Medicine, Department of Neurobiology, Fairchild Science Building D235, Stanford, CA 94305-5125. E-mail: barres@stanford.edu.

Copyright (C) 2001 Society for Neuroscience $0270-6474 / 01 / 211538-09 \$ 15.00 / 0$
1999), but it is not known how they are signaled to survive, proliferate, and differentiate.

We recently developed an immunopanning method to purify APCs from developing embryonic rat optic nerves and characterized their antigenic and developmental properties in culture (Mi and Barres, 1999). We found that the Pax2 transcription factor is specifically expressed by all astrocyte lineage cells in the optic nerve throughout their development but not by oligodendrocytes or other cell types. APCs are $\mathrm{GFAP}^{-} / \mathrm{S} 100 \beta^{-} / \mathrm{A} 2 \mathrm{~B} 5^{+} /$ $\mathrm{Pax} 2^{+}$, whereas optic nerve astrocytes are $\mathrm{GFAP}^{+} / \mathrm{S} 100 \beta^{+} /$ $\mathrm{A} 2 \mathrm{~B} 5{ }^{-} / \mathrm{Pax} 2^{+}$. Unlike astrocytes, purified APCs die in serumfree culture but can be stimulated to survive and divide by bFGF or by glial growth factor. In addition, purified APCs do not differentiate constitutively in serum-free culture but are induced to differentiate into glial fibrillary acid protein $\left(\right.$ GFAP) ${ }^{+}$astrocytes by CNTF or LIF. We also found that differentiation of purified APCs in culture is signaled by non-neural optic nerve cells and not by retinal ganglion cells.

These studies raised two questions. What is the identity of the non-neural cell type within the optic nerve that induces APCs to differentiate into astrocytes, and does this cell type signal differentiation by secreting either LIF or CNTF? Because the main two types of non-neural cells within the embryonic optic nerve are pial cells and endothelial cells and optic nerve astrocytes contact both of these cell types extensively (Suarez and Raff, 1989), we specifically studied the effects of each of these cell types on astrocyte differentiation. Here we describe simple immunopanning methods for purifying optic nerve endothelial cells and for enriching pial cells. Using these methods, we show that endothelial cells, but not pial cells, within the optic nerve induce APCs to differentiate into astrocytes. We also show that endothelial cells produce LIF, which helps to promote astrocyte differentiation in vitro. These findings, together with recent findings that mice lacking LIF receptors have impaired astrocyte differ- 
entiation, suggest that endothelial cells promote astrocyte differentiation in vivo and that they do this, at least in part, via LIF or LIF-like cytokines.

\section{MATERIALS AND METHODS}

Detailed step-by-step protocols for all procedures are available on request (barres@stanford.edu).

Reagents. Recombinant trophic factors were obtained from Peprotech (Rocky Hill, NJ) (bFGF), Regeneron Pharmaceuticals (Tarrytown, NY) (CNTF), and R \& D Systems (Minneapolis, MN) (LIF). Monoclonal antibodies were obtained from Serotec (Indianapolis, IN) (MRC-OX7 anti-Thy1.1 IgG antibody), Jim Cohen (Guy's Hospital, London, UK) (C5 neuroepithelial antibody), Sigma (St. Louis, MO) (anti-S100 $\beta$ antibody), and R \& D Systems (anti-mLIF and anti-CNTF antibodies). Polyclonal antibodies were obtained from R \& D Systems [rabbit anti-von Willebrand factor (VWF) antibody], Babco (Richmond, CA) (rabbit anti-Pax2 antiserum), Santa Cruz Biotechnology (Santa Cruz, CA) (rabbit anti-Tie-2 antiserum), and Dako (Carpinteria, CA) (rabbit antiGFAP antiserum). Bandeiraea simplifonica lectin I (BSLI) was obtained from Sigma.

Preparation of optic nerve cell suspension. Sprague Dawley rats (Simonson Laboratories, Gilroy, CA) were used for all experiments. The date of plugging was embryonic day 0 (E0). All embryos were examined to verify their ages, and obviously overage embryos were discarded.

Embryonic and postnatal optic nerves were dissected and enzymatically dissociated using papain as described previously (Barres et al., 1992). In brief, minced optic nerves were incubated at $37^{\circ} \mathrm{C}$ for $45 \mathrm{~min}$ [postnatal day $1(\mathrm{P} 1)$ ] or $30 \mathrm{~min}(\mathrm{E} 17)$ in a papain solution $(33 \mathrm{U} / \mathrm{ml}$; Worthington, Freehold, NJ) in DPBS (Life Technologies, Rickville, MD) containing L-cysteine $(0.4 \mathrm{mg} / \mathrm{ml})$ and DNase $(125 \mathrm{U} / \mathrm{ml})$. The tissues were then triturated sequentially in a solution containing ovomucoid $(2 \mathrm{mg} / \mathrm{ml})$, DNase $(125 \mathrm{U} / \mathrm{ml})$, and BSA $(1 \mathrm{mg} / \mathrm{ml})$ to yield a suspension of single cells. The cells were recovered by centrifugation at $1000 \times g$. On average, $\sim 13,000$ or 15,000 cells were obtained from each E17 or P1 optic nerve, respectively.

Purification of astrocyte precursor cells, vascular endothelial cells, and pial cells by sequential immunopanning. Optic nerve astrocyte precursor cells from E17 rats were purified by sequential immunopanning as described previously (Mi and Barres, 1999). In brief, cell suspensions were incubated first on a panning dish coated with the MRC-OX7 Thy1.1 antibody to deplete microglia and meningeal cells. The remaining neuroepithelial cells were selected on the second dish coated with the C5 anti-neuroepithelial antibody (Miller et al., 1984). The purified cells were recovered by trypsin digestion from the panning dish for additional experiments. An average of $\sim 5000$ precursor cells were obtained from each E17 optic nerve. This represented a yield of $>90 \%$ of the precursor cells present in the cell suspensions that had survived the optic nerve dissociation procedure. Their purity was $>95 \%$ pure, with the few percent contaminating cells being astrocytes that had already differentiated from APCs by E17 (Mi and Barres, 1999).

Vascular endothelial cells (VECs) and pial cells were purified as follows. E17 or P1 optic nerves were enzymatically dissociated as described previously (Mi and Barres, 1999). The cells were incubated in the first dish coated with the C5 antibody to deplete all of the astrocyte lineage cells, microglia (E17 and P1), and oligodendrocyte lineage cells (P1). The remaining cells, which contained only vascular endothelial cells and pial cells, were incubated in a second dish coated with BSLI, which binds to all the vascular endothelial cells that were recovered by trypsin treatment. The cells that did not adhere to the BSLI dish consisted primarily of pial cells.

Coculture of APCs with vascular endothelial cells or pial cells. Approximately 20,000-30,000 purified vascular endothelial cells or pial cells in 10-20 $\mu \mathrm{l}$ of medium were plated onto a 24 well culture dish (Falcon Instruments, Florence, Italy) or onto $1.2 \mathrm{~cm}$ glass coverslips (Marienfeld, Lauda-Königshofen, Germany), both of which were precoated with polyD-lysine (70 kDa; $10 \mu / \mathrm{ml}$; Sigma) and cultured for $10-15 \mathrm{~min}$. The cells were then cultured in $500 \mu \mathrm{l}$ of the B-S serum-free medium [modified from Bottenstein and Sato (1979), as described previously (Mi and Barres, 1999)] containing insulin ( $5 \mu \mathrm{g} / \mathrm{ml}$; Sigma). After $3 \mathrm{~d}$ of culture, another $500 \mu \mathrm{l}$ of medium were added to each well. Cells were then fed every $3 \mathrm{~d}$ by replacing half of the medium $(500 \mu \mathrm{l})$ with fresh media. Cells were conditioned for at least $3 \mathrm{~d}$ before the coculture experiments.
Approximately 5000 purified APCs were cultured on poly-D-lysinecoated glass coverslips with the B-S serum-free medium containing bFGF, insulin, and CPT-cAMP for $1 \mathrm{hr}$. The cells were then washed several times with Neurobasal medium (Life Technologies), added to the vascular endothelial cell or pial cell separated by glass chips, and replaced with $500 \mu \mathrm{l}$ of conditioned medium with fresh B-S serum-free medium containing insulin. Cells were cultured for $4 \mathrm{~d}$ before immunofluorescence staining (see below).

For antibody neutralization experiments, vascular endothelial cell or pial cell cultures were conditioned for at least $3 \mathrm{~d}$. The conditioned media $(250 \mu \mathrm{l})$ were added to purified APCs that had been cultured for $1 \mathrm{hr}$ with B-S serum-free medium containing bFGF, insulin, and chlorphenylthio (CPT)-cAMP, and another $250 \mu \mathrm{l}$ of fresh B-S serum-free medium containing insulin was added. The cells were fed daily with both conditioned and fresh media.

In the experiment with neutralizing antibodies, conditioned vascular endothelial cell medium was incubated with anti-mLIF antibody (50 $\mu \mathrm{l} / \mathrm{ml})$, anti-mLIF antibody plus LIF $(0.1 \mu \mathrm{g} / \mathrm{ml})$, anti-CNTF antibody $(50 \mu \mathrm{g} / \mathrm{ml})$, or without any antibody or factors at $4^{\circ} \mathrm{C}$ overnight. The media were centrifuged at $5000 \times g$ for 2 min and added to APCs that had been cultured for $1 \mathrm{hr}$ with B-S serum-free medium containing bFGF, insulin, and CPT-cAMP. An equal volume of fresh B-S serumfree medium containing insulin was added. The cells were fed daily with both the neutralized and fresh media. Cells were cultured for $4 \mathrm{~d}$ before immunofluorescence staining (see below).

Cryosection of optic nerves. Optic nerves were dissected and fixed in ice-cold $4 \%$ paraformaldehyde for $1 \mathrm{hr}$ and infiltrated in $30 \%$ sucrose overnight at $4{ }^{\circ} \mathrm{C}$. The nerves were then sectioned longitudinally into 8 - $\mu \mathrm{m}$-thick cryosections that were collected on precoated slides (Sigma) and left at room temperature for $\sim 30 \mathrm{~min}$ to air dry. The sections were stored at $-30^{\circ} \mathrm{C}$ until staining.

Immunofluorescence staining. The cryosections were baked at $50^{\circ} \mathrm{C}$ for $15 \mathrm{~min}$ to ensure the attachment of tissues to the slides. After fixation with $4 \%$ paraformaldehyde for $10 \mathrm{~min}$ at room temperature and a $30 \mathrm{~min}$ incubation in blocking buffer $(50 \%$ normal goat serum solution containing $150 \mathrm{~mm} \mathrm{NaCl}, 50 \mathrm{~mm}$ Tris, pH7.4, $1 \%$ BSA, $100 \mathrm{~mm}$ L-lysine, and $0.2 \%$ Triton $\mathrm{X}-100)$ to block nonspecific binding, the cryosections of optic nerves were stained with the polyclonal anti-GFAP, anti-von Willebrand factor antibodies, or mouse anti-rat monoclonal anti-platelet endothelial cell adhesion molecule (PECAM1) antibodies overnight, followed by the incubation for $1 \mathrm{hr}$ with a fluorescein-coupled goat anti-rabbit IgG antibody (Jackson ImmunoResearch, West Grove, PA) and rhodamine-conjugated Bandeiraea lectin. The sections were postfixed with $4 \%$ paraformaldehyde for $10 \mathrm{~min}$ to prevent the diffusion of Bandeiraea lectin staining. Cultured cells on coverslips were treated similarly, except shorter incubation times were used.

The stained sections and cultures were mounted with Citiflour (Chemistry Laboratory, University of Kent, Kent, UK) and sealed with nail varnish. A Nikon (Tokyo, Japan) Microphot-FXA microscope was used to observe, count, and photograph the fluorescence staining. Values from all experiments involving counting of antigenic phenotypes are shown as means $\pm \mathrm{SD}(n=3)$. All results shown were repeated in at least three separate experiments.

Reverse transcription-PCR analysis. E17 APCs were purified as described above. VECs and pial cells were purified as above, except that P1 optic nerves were used because of the small numbers of endothelial and pial cells in E17 optic nerves. Whole E17 retinas were isolated and used without cell dissociation. A total of 200 optic nerves and 100 retinas were used in this experiment. The purified cells were cultured on a panning dish for $\sim 1 \mathrm{hr}$ and then lysed using the Qiagen (Hilden, Germany) total RNA purification kit. mRNA was reverse transcribed using Superscript II (Life Technologies) with an oligo-dT primer $(10 \mu \mathrm{M})$ in a $35 \mu$ reaction containing $1 \mu \mathrm{l}$ of Superscript II RT buffer, $10 \mu \mathrm{M}$ each dATP, dTTP, $\mathrm{dCTP}$, and dGTP, and $20 \mathrm{U}$ of RNasin (Life Technologies). After $2 \mathrm{hr}$ at $42^{\circ} \mathrm{C}$, the reaction was terminated by adding $365 \mu \mathrm{l}$ of $\mathrm{H}_{2} \mathrm{O}$ and boiling for 2 min. For PCR amplification, specific oligodendrocyte primer pairs (0.5 $\mu \mathrm{M}$ each) were incubated with $1 \mu \mathrm{l}$ of cDNA and $1 \mathrm{U}$ of Taq polymerase (PerkinElmer Life Sciences, Emeryville, CA) in a PCR solution (Boehringer Mannheim, Indianapolis, IN). Typical cycle parameters were $1 \mathrm{~min}$ at $94^{\circ} \mathrm{C}, 1 \mathrm{~min}$ at $56^{\circ} \mathrm{C}$, and $1 \mathrm{~min}$ at $72^{\circ} \mathrm{C}$ for 39 cycles, followed by a cycle at $72^{\circ} \mathrm{C}$ for $10 \mathrm{~min}$. The whole reaction was then fractionated on $1.2 \%$ regular agarose gel, and the PCR product was visualized by ethidium bromide staining. The primers for reverse transcription 


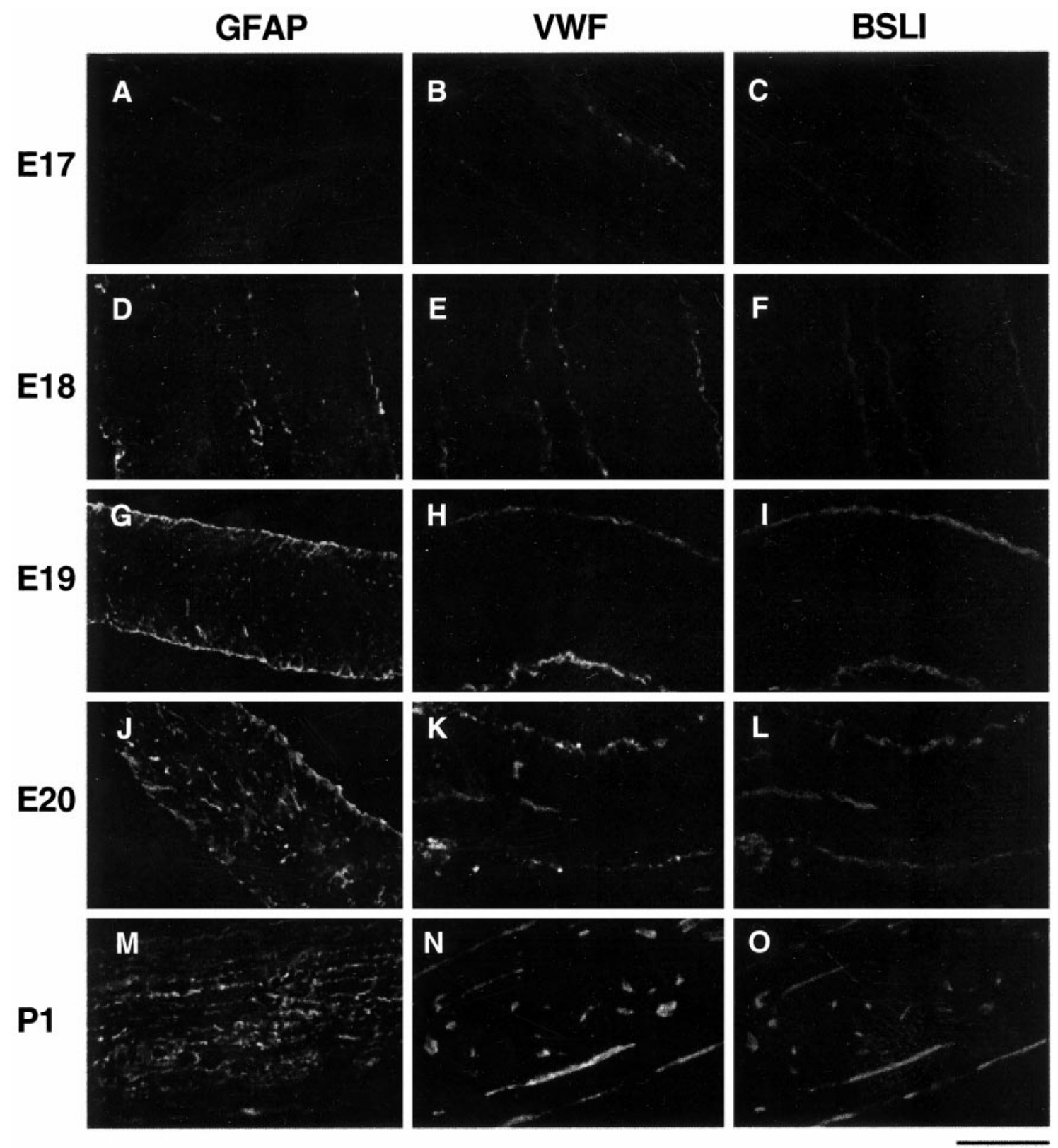

Figure 1. Temporal and spatial correlation of astrocyte differentiation and vascularization in the developing optic nerve. Longitudinal cryosections of developing rat optic nerves from E17 $(A-C), \mathrm{E} 18(D-F), \mathrm{E} 19(G-I), \mathrm{E} 20(J-L)$, and $\mathrm{P} 1(M-O)$ were stained by a GFAP antiserum $(A, D, G, J, M)$, which is a specific marker of astrocytes. GFAP staining was scarce at E17 but was first detected near the surface of the nerve at E18. The intensity of the staining increased with age, extending more deeply into the nerve. The staining extended throughout the nerve by P1. Optic nerve sections of the same ages were double by two endothelial-specific markers, a VWF antiserum $(B, E, H, K, N)$ and rhodamine-conjugated BSLI $(C, F, I, L, O)$. VWF and BSLI labeling colocalized and displayed a similar time course and pattern to the GFAP staining. Scale bar, $100 \mu \mathrm{m}$

(RT)-PCR analysis are as follows: LIF, 5' primer, CAGTGCCAATGCCCTCTTTA, and $3^{\prime}$ primer, AAAGGAAGAAGTTGGGCTGC; and glyceraldehyde-3-phosphate dehydrogenase (GAPDH), 5' primer, ATTGTCAGCAATGCATCCTGCA, and 3' primer, AGACAACCTGGTCCTCAGTGTA.

\section{RESULTS}

\section{Temporal and spatial correlation of endothelial and} astrocyte differentiation

To determine the relationship between astrocyte differentiation and blood vessel formation in the developing rat optic nerve, cryosections of embryonic and neonatal optic nerves were immunostained by polyclonal antibodies directed against GFAP, a specific astrocyte marker, and VWF, a specific vascular endothelial marker (Fig. 1). At E17, most of the astrocyte lineage cells within the nerve are APCs (Mi and Barres, 1999). Thus, little GFAP staining was detected in the E17 optic nerve (Fig. 1A), indicating that few astrocytes have been generated yet. At E18 and E19, GFAP staining was detected with increasing intensity but mostly near the surface of the nerve fiber (Fig. $1 D, G$ ), just underneath the pia (Fig. 2). By E20, increasing GFAP staining was detected more deeply within the optic nerve parenchyma (Fig. $1 J$ ). By P1, all of the astrocyte lineage cells were $\mathrm{GFAP}^{+}$(Fig. $1 M$ ), as described previously (Mi and 

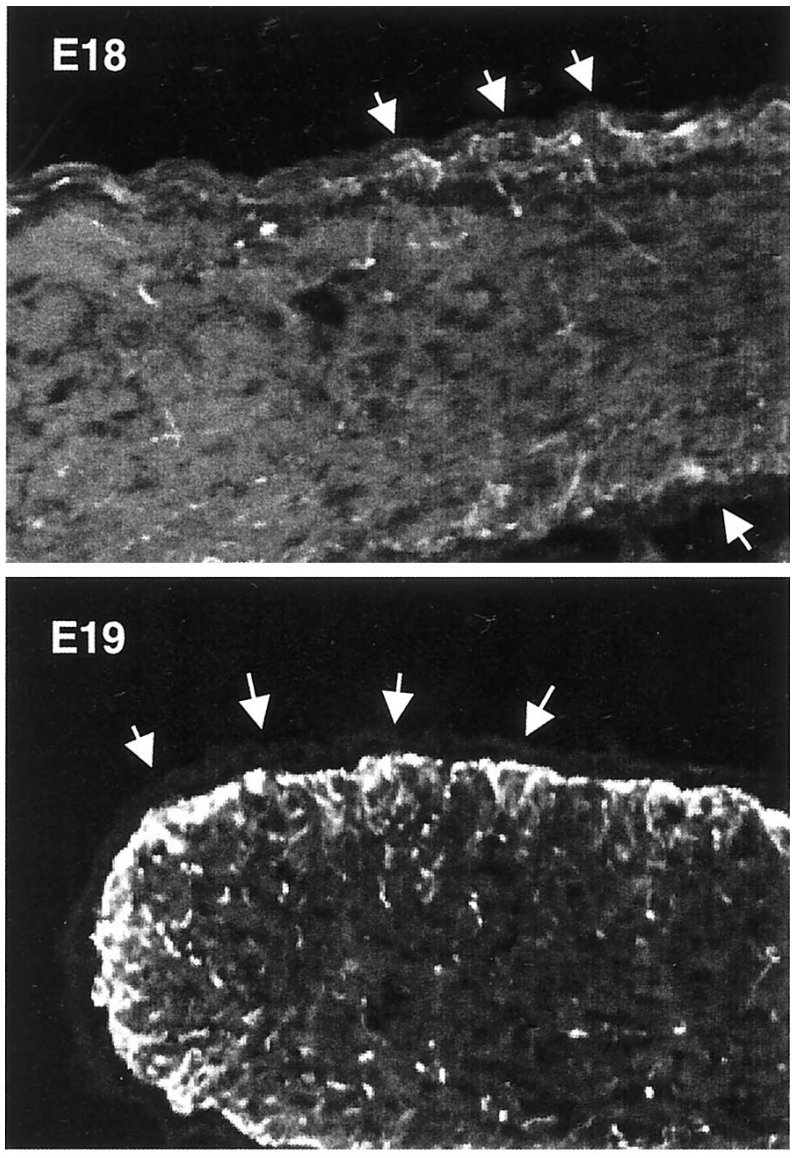

Figure 2. GFAP staining in developing optic nerves. Longitudinal cryosections of E18 and E19 optic nerves were stained by an anti-GFAP antibody and observed under higher magnification than that shown in Figure 1. The majority of GFAP staining at E18 is near the surface of the nerve, right underneath the pia (arrows). By E19, the staining beneath the pia has become much more intense and is beginning to extend more deeply into the nerve. Scale bar, $50 \mu \mathrm{m}$.

Barres, 1999). An identical pattern was observed when antibodies to the astrocyte-specific marker $\mathrm{S} 100 \beta$ was used (data not shown). These findings demonstrate that astrocytes are generated in a spatial gradient that progresses from the surface of the nerve toward the inside of the nerve.

The generation of endothelial cells, as demonstrated by VWF staining, corresponded closely to the appearance of GFAP staining both temporally and spatially. At E17, there was only light VWF staining along the surface of the optic nerve (Fig. $1 B$ ). The staining increased with age (Fig. 1E,H) and was easily detected in capillary-like structures in the middle of the nerve by E20 (Fig. $1 K$ ). By P1, the staining could be detected on small blood vessels throughout the entire nerve (Fig. $1 N)$. An identical pattern of labeling was observed when the optic nerve sections were stained by rhodamine-conjugated BSLI (also called Griffonia simplicifolia lectin I) (Fig. $1 C, F, I, L, O$ ), or by an anti-PECAM antiserum (data not shown), which are two other specific markers of endothelial cells (Laitinen, 1987; Minamikawa et al., 1987; Tontsch and Bauer, 1989; Newman 1997; Hatzopoulos et al., 1998). These observations indicate that there is a close temporal and spatial correlation between astrocyte differentiation and vascularization within the optic nerve.

\section{Purification of vascular endothelial cells and pial cells from developing rat optic nerves}

The progression of astrocyte differentiation from the outside to the inside of the nerve might be explained either by a pial or an endothelial inducing signal. Therefore, we next developed a sequential panning method to purify the VECs and the pial cells. Within the developing optic nerve, there are five main cell types: microglia, astrocyte lineage cells, oligodendrocyte lineage cells, VECs, and pial cells. Each glial cell type expresses a characteristic surface antigenic phenotype that allows them to be purified by panning (Barres et al., 1992; Mi and Barres, 1999). Similarly, VECs and pial cells can be identified by their surface antigenic phenotype and are $\mathrm{BSLI}^{+}$and Thy $1^{+}$, respectively.

To purify the VECs and pial cells, we incubated E17 or P1 enzymatically dissociated optic nerve cells first on panning dishes coated with the anti-neuroepithelial cell C5 antibody (Miller et al., 1984). This eliminated all neural cells from the optic nerve cell suspension, primarily astrocyte and oligodendrocyte lineage cells. Microglia adhered nonspecifically to the dish also, via their Fc receptors. The remaining cells consisted primarily of two non-neural cell types: VECs and pial cells. These cells were incubated on a dish coated with BSLI, which selected the VECs. The remaining cells in suspension that did not adhere to either the C5 or BSLI dishes were primarily pial cells. The VECs were removed from the BSLI dish by trypsinization.

To verify the purity of the VEC and pial fractions, we cultured each of these cell fractions at high density in serumfree medium containing insulin. Under these conditions, both cell fractions survived well, as evidenced by few apoptotic cells in the cultures, and displayed distinct morphologies. Cells in the BSLI fraction were highly morphologically homologous, displaying a spindle shape (Fig. $3 A$ ). More than $99.9 \%$ of these cells were brightly labeled by the specific vascular endothelial specific marker Tie2 (Fig. $3 C, D$ ), as well as by the VWF antiserum (data not shown), and did not stain with markers of astrocyte lineage cells or microglia as judged by the expression of Pax2 and Fc receptors, respectively. Cells in the pial cultures nearly all displayed the characteristic flat sheet-like morphology of pial fibroblasts and were not stained by Tie2 or VWF antibodies (Fig. 3B).

\section{Effects of purified vascular endothelial cells on astrocyte differentiation in developing rat optic nerve}

We have shown previously that APCs are induced to differentiate into astrocytes by LIF, CNTF, or a signal secreted by non-neural cells in the optic nerve (Mi and Barres, 1999). To determine which non-neural cell type induces astrocyte differentiation, we cocultured purified E17 APCs over a conditioning layer of purified VECs or purified pial cells. After $4 \mathrm{~d}$, we stained them with the GFAP antiserum. As we reported previously, in the absence of an inducing signal, the majority of the purified APCs remain $\mathrm{GFAP}^{-}$, whereas in response to LIF, nearly all differentiate into GFAP $^{+}$astrocytes (Figs. $4 A$, $5 A, B)$. When we cocultured the APCs together with pial cells that had been purified from either E17 or P1 optic nerves, astrocyte differentiation was not promoted (Figs. 4A, 5C,D). Consistent with our previous observation that non-neural cells promoted the proliferation of APCs, however, we observed that, in the presence of pia, the APCs proliferated significantly 

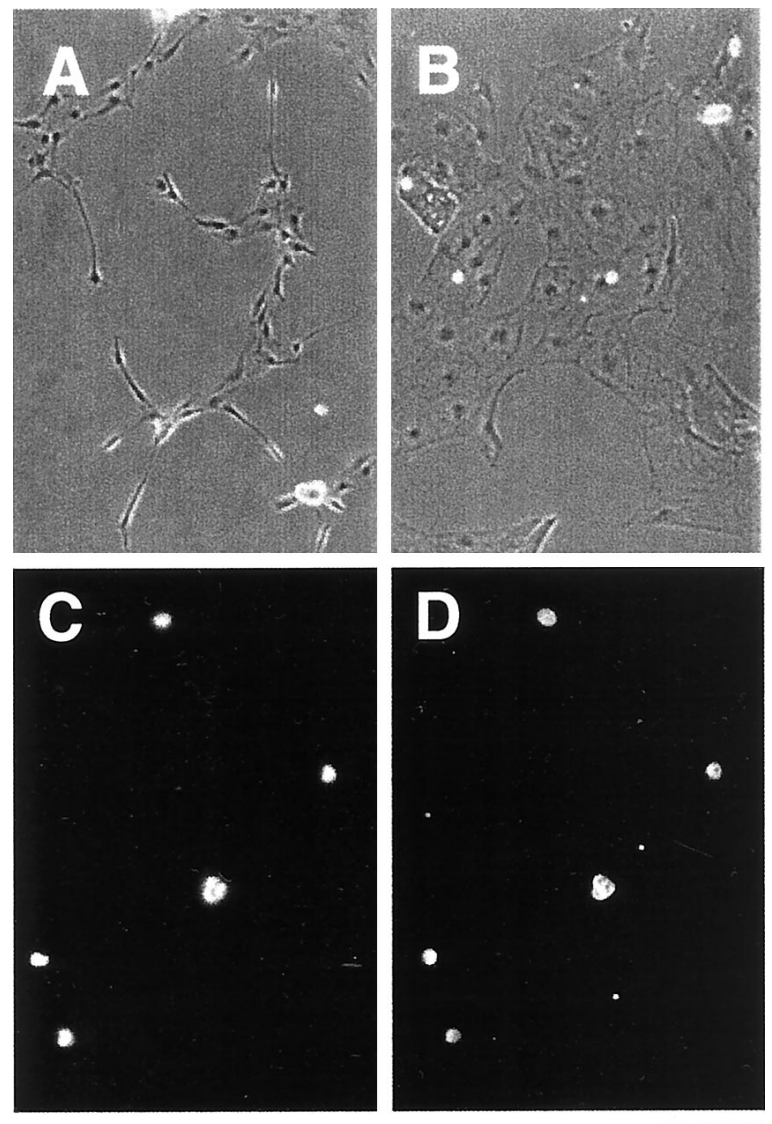

Figure 3. Morphology and immunoreactivity of purified VECs in culture. Phase-contrast micrographs of purified VECs $(A)$ and pial cells $(B)$ after $3 \mathrm{~d}$ in serum-free culture. VECs tend to be spindle-shaped $(A)$, whereas the pial cells display a flat sheet-like appearance $(B)$. To confirm the purity of the VECs, they were immunostained immediately after isolation with an anti-Tie2 antibody $(C, D)$. All of the purified cells, indicated in $(C)$ with the $4^{\prime}, 6^{\prime}$-diamidino-2-phenylindole (DAPI) nuclear stain, were Tie $2^{+}(D)$. Scale bar, $100 \mu \mathrm{m}$.

faster, because many more cells were observed in those cultures after $4 \mathrm{~d}$ (data not shown).

When we cocultured the APCs together with VECs that had been purified from either E17 or P1 optic nerves, astrocyte differentiation was as strongly promoted as it was in response to plateau concentrations of LIF (Figs. $4 A, 5 E, F$ ). The majority of APCs differentiated into $\mathrm{GFAP}^{+}$astrocytes when cocultured with either E17 or P1 VECs. Moreover, these cells displayed the typical morphology of type-1 astrocytes and expressed several other characteristic markers, including the glial form of the glutamate transporter, GLT-1, and S100 $\beta$ as assessed by immunostaining. In contrast to the pial cells, an effect of VECs on proliferation of the APCs was not noticeable. These results show that VECs secrete a soluble signal that, like LIF, induces APCs to differentiate into astrocytes.

\section{Effect of neutralizing antibody on astrocyte differentiation promoted by vascular endothelial cells}

Both LIF and CNTF induce APCs to differentiate into astrocytes. To determine whether LIF or CNTF protein is the astrocyte differentiation-inducing signal released by VECs, we examined the effects of anti-LIF and anti-CNTF neutralizing
A

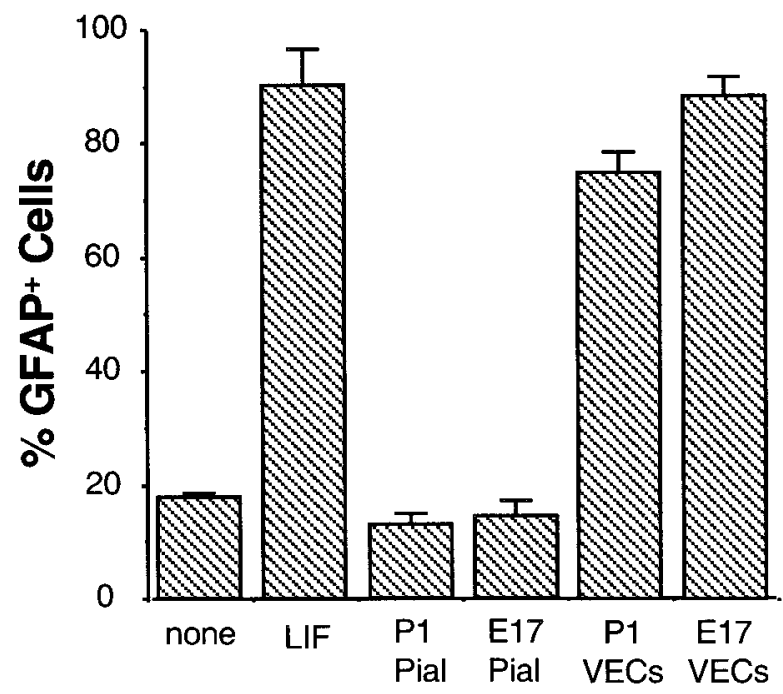

B

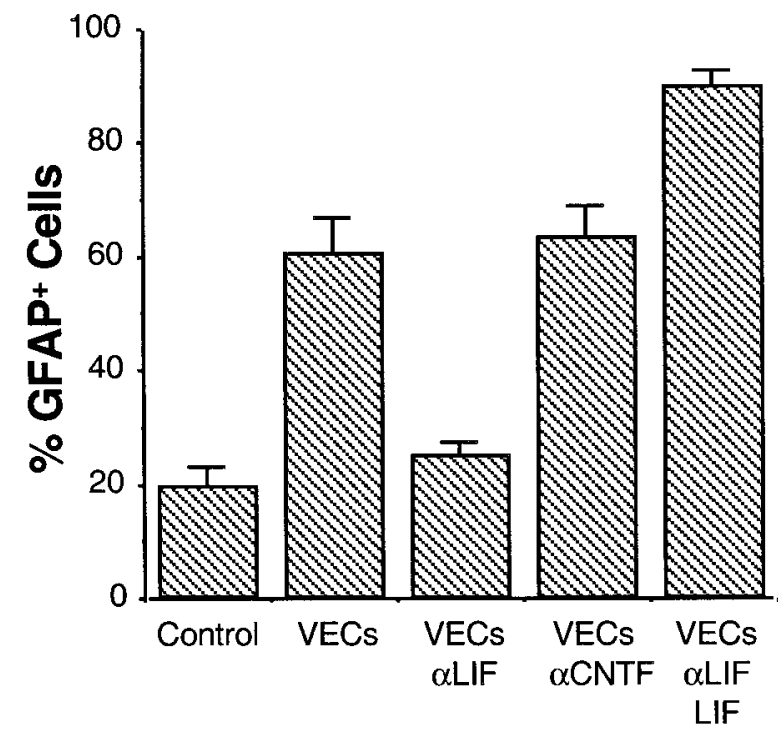

Figure 4. Effects of purified VECs and pial cells on astrocyte differentiation. $A$, Purified APCs were cultured on a coverslip suspended above a conditioning layer of purified VECs or pial cells, as indicated. APCs cultured alone (none) or with LIF (LIF) were used as negative and positive controls. After $4 \mathrm{~d}$, the APCs cultures were labeled with a GFAP antiserum. Astrocyte differentiation was significantly promoted by VECs purified either from both E17 and P1 optic nerves but not by pial cells purified from nerves of either age. Results represent means $\pm \mathrm{SD}(n=3)$. $B$, Effect of LIF neutralizing antibody on astrocyte differentiation promoted by VECs. VEC-conditioned medium was collected and incubated overnight at $4^{\circ} \mathrm{C}$ with nothing (VECs), neutralizing antibody against LIF (VECs $\alpha L I F)$, neutralizing antibody against CNTF (VECs $\alpha C N T F$ ), or neutralizing antibody against LIF plus excess LIF (VECs $\alpha L I F L I F$ ). Purified APCs were then cultured in these conditioned media for $4 \mathrm{~d}$ before GFAP immunostaining. The ability of VEC-conditioned medium to induce astrocyte differentiation was significantly reduced by the LIF neutralizing antibody unless excess LIF was added to the medium. Results represent means $\pm \operatorname{SD}(n=3)$. 


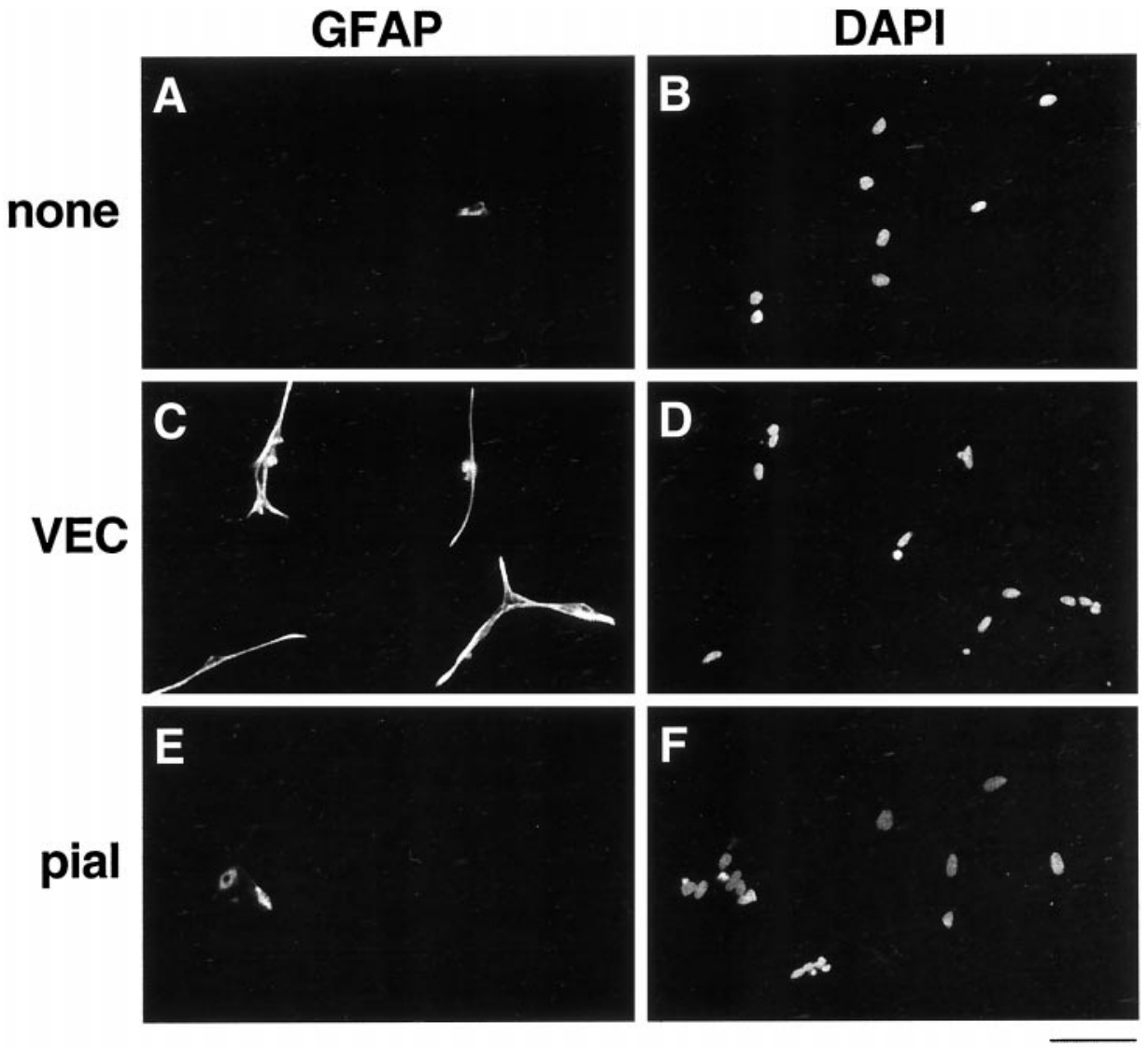

Figure 5. Effect of VECs on astrocyte differentiation. Purified APCs were cultured alone $(A, B)$ or suspended above a conditioning layer of purified VECs $(C, D)$ or pial cells $(E, F)$. After $4 \mathrm{~d}$, the APC cultures were stained with an anti-GFAP antibody $(A, C, E)$, as well as the DAPI nuclear stain $(B, D, F)$. Most APCs remain undifferentiated unless cultured with VECs. Scale bar, $100 \mu \mathrm{m}$.

antibodies on VEC-induced astrocyte differentiation. In this experiment, to ensure optimal neutralization of any cytokines released by the VECs, we cultured purified APCs in medium that had been conditioned by VECs rather than coculturing the APCs above a conditioning layer of VECs. As in the cocultures, when APCs were cultured in VEC-conditioned medium for $4 \mathrm{~d}$, there was a strong induction of $\mathrm{GFAP}^{+}$astrocyte differentiation (Fig. 4B). This inducing effect was nearly entirely abolished when the neutralizing anti-LIF antiserum was added to the VEC-conditioned medium (Figs. $4 B, 6 A, B$ ). In contrast, the neutralizing anti-CNTF antiserum did not decrease the ability of the VEC-conditioned medium to induce astrocyte differentiation (Figs. $4 B, 6 C, D$ ). The ability of the neutralizing anti-LIF antiserum to prevent the VEC-induced astrocyte differentiation was completely overcome by addition of excess LIF to the VEC-conditioned medium, providing additional evidence that the anti-LIF antibody blocked APC differentiation in response to the VEC-conditioned medium by specifically neutralizing LIF (Figs. $4 B, 6 E, F$ ). These results show that VECs induce astrocyte differentiation in vitro by secreting LIF. To investigate whether LIF also promotes astrocyte differentiation in the developing optic nerve, we measured the percentage of astrocyte lineage cells that were astrocytes (as opposed to APCs) by immunostaining cryosections of P1 optic nerves obtained from LIF-deficient mice. Greater than $99 \%$ of APCs had differentiated into astrocytes, indicating that there was no significant delay in astrocyte differentiation in the absence of LIF (see Discussion).

\section{Expression of LIF mRNA by vascular endothelial cells}

These results are consistent with the release of LIF, but not CNTF, protein by VECs. It has already been shown that CNTF is not made within the optic nerve until the first postnatal week (Stockli et al., 1991). To determine whether LIF mRNA transcripts are expressed in embryonic optic nerve, we performed RT-PCR on acutely isolated E18 optic nerve cells. We examined both the neural cells, which are primarily APCs ( $\mathrm{C}^{+}$fraction), the $\mathrm{VECs}\left(\mathrm{BSLI}^{+}\right.$fraction), and a cell fraction enriched for pial cells (C5 ${ }^{-}, \mathrm{BSLI}^{-}$fraction; see Materials and Methods). A strong signal indicative of LIF transcripts in the VECs $\left(\mathrm{BSLI}^{+}\right)$was detected (Fig. 7), whereas only a weak mRNA signal could be detected in the pial cells and no LIF mRNA was detected in the retinal cells. The high LIF mRNA signal in the vascular endothelial cell fraction reflects expression of LIF by the VECs because this fraction was purified by positive selection and was $>99.9 \%$ pure. However, the weak LIF signal detected in the pial cells might reflect contamination by VECs or other cell types because these cells were selected by negative selection and represented all of the cells that did not adhere to panning dishes coated with the other antibodies (see Materials and Methods). Surprisingly, a very weak, but detectable, LIF mRNA signal was observed in acutely isolated APCs, most likely arising from $\sim 5 \%$ of astrocyte lineage cells in that fraction that have already differentiated into $\mathrm{GFAP}^{+}$astrocytes (see Discussion). Transcripts were detected in control PCR using GAPDH primers but not in the reaction without reverse transcription, indicating that the 
Figure 6. Effect of LIF neutralizing antibody on astrocyte differentiation induced by VECs. Purified APCs were cultured in VECconditioned medium treated with anti-LIF antibody $(A, B)$, anti-CNTF antibody $(C, D)$, or anti-LIF antibody plus excess $\operatorname{LIF}(E, F)$. After $4 \mathrm{~d}$, the APC cultures were stained with an anti-GFAP antiserum $(A, C, E)$ and the DAPI nuclear stain $(B, D, F)$. Few APCs differentiate into $\mathrm{GFAP}^{+}$astrocytes in the presence of the LIF neutralizing antibody.
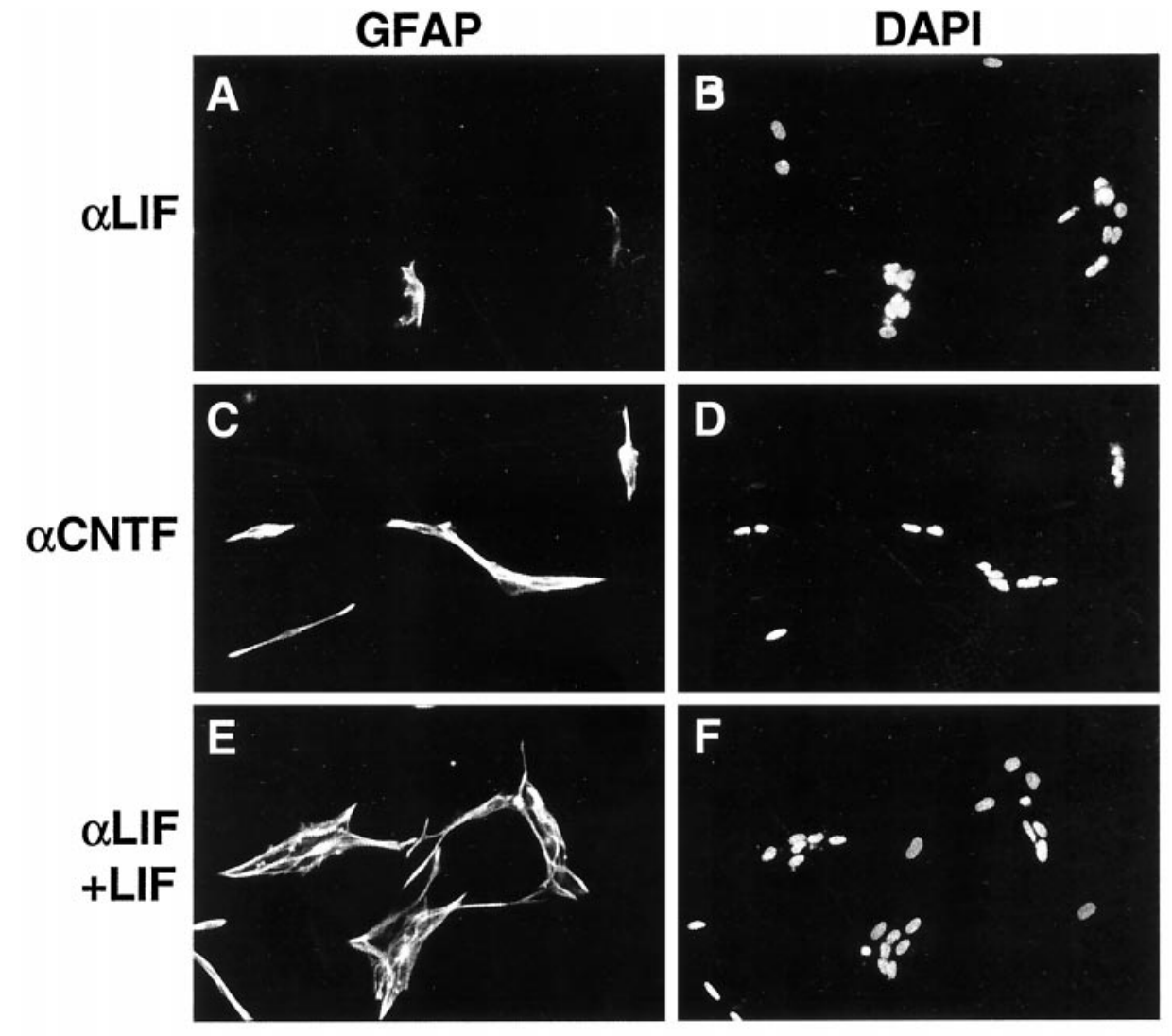

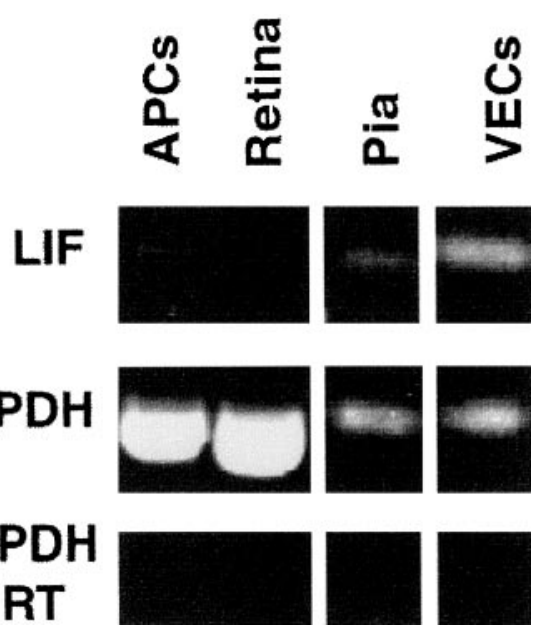

Figure 7. RT-PCR analysis of LIF mRNA in optic nerve and retina. Total RNA was extracted from E17 retinas, purified E17 APCs, and from VECs and pial cells isolated from P1 optic nerves. Subsequently, total RNA was subjected to RT-PCR using LIF-specific primers. RT-PCR or PCR without reverse transcription using GAPDH primers were used as controls. The amplified products were separated on a $1.5 \%$ agarose gel and visualized by ethidium bromide.

PCR products observed were generated from cDNA rather than from genomic DNA. Together, these results show that acutely isolated VECs express LIF mRNA and are the main source of LIF mRNA within embryonic optic nerves.

\section{DISCUSSION}

\section{Endothelial cells induce astrocyte differentiation in vitro}

The present findings demonstrate that endothelial cells are sufficient to signal astrocyte differentiation in vitro and strongly suggest that they are also likely to play an important role in controlling astrocyte differentiation in vivo. First, we observed a close correlation between when and where astrocytes differentiated and blood vessels formed. Second, we found that serum-free medium conditioned by highly purified endothelial cells was sufficient to induce APCs to differentiate, whereas no other embryonic optic nerve cells types, pial cells, or retinal ganglion cells were able to induce their differentiation. In addition, we found that acutely isolated VE cells from the embryonic optic nerve expressed LIF mRNA and that anti-LIF antibodies blocked endothelial induction of astrocyte differentiation in vitro.

Together, these results strongly suggest that endothelial cells may be necessary and sufficient to induce astrocyte differentiation within the optic nerve. More definitive proof of a controlling role of endothelial cells would be to show that astrocytes fail to develop in vivo in the absence of endothelial cells. However, transgenic mice defective in vasculogenesis and angiogenesis die long before astrocyte generation. We have attempted to assess whether vascular endothelial cells promote astrocyte differentiation in intact optic nerves placed into explant culture. However, APCs rapidly died in these explanted nerves. Even when their survival was promoted by the inclusion of cAMP analogs or neuregulin- 1 in the culture medium, we were unable to accelerate or delay vascular development by including vascular endothelial 
growth factor (VEGF) or anti-VEGF antibodies in the culture medium. Other investigators have also had similar difficulty manipulating vascularization in explant culture; additional attempts to manipulate vascular development in brain slices and optic nerve will be greatly aided by technical advances.

We have primarily examined the development of astrocytes within the optic nerve; however, it is likely that endothelial cells also induce the differentiation of astrocytes in other brain regions. Most astrocytes develop postnatally after most neurons have been generated, which corresponds well with the timing of angiogenesis. For instance, in the developing brain, astrocyte differentiation is closely linked, both spatially and temporally, to vascularization (Marin-Padilla, 1995; Zerlin et al., 1995; Zerlin and Goldman, 1997). The ability of endothelial cells to induce astrocyte differentiation is not surprising in view of the close anatomic and functional relationship of astrocytes and endothelial cells. In the brain, capillaries and small arterioles are completely ensheathed by astrocyte end feet, in which they help to relay nutrients from the blood to neurons and maintain a blood-brain barrier (Peters et al., 1991; Rubin and Staddon, 1999). The induction of astrocyte differentiation by endothelial cells also fits well with phylogenetic observations (Penfield, 1932). In early vertebrates such as turtles, which have a thin cortex, the brain is not vascularized; diffusion into the brain from the CSF is sufficient to provide nutrients and remove wastes. In these lower vertebrates, there are no astrocytes but instead are radial ependymoglial-like cells that extend from the ventricular lumen to the brain surface and may serve similar functional roles. In higher vertebrates, astrocytes evolve simultaneously with the phylogenetic thickening of brain tissue and the appearance of vasculature. Presumably the astrocytes then assume similar functions to radial ependymoglial cells in lower vertebrates.

\section{Endothelial cells induce astrocyte differentiation, at least in part, by secreting LIF}

LIF has repeatedly been shown to induce both multipotent neural stem cells and astrocyte precursor cells to differentiate into astrocytes in culture (Yoshida et al., 1993; Nakagaito et al., 1995; Johe et al., 1996; Richards et al., 1996; Bonni et al., 1997; Mi and Barres, 1999; Galli et al., 2000). Recent work suggests that LIF helps to induce astrocyte differentiation in vivo. Embryonic brains and spinal cords from transgenic mice deficient in LIF receptors or its associated subunit gp130 contain few GFAP-expressing astrocytes (Ware et al., 1995; Koblar et al., 1998; Nakashima et al., 1999b). In addition, adult transgenic mice deficient in LIF have a significant decrease in hippocampal astrocytes, particularly in females (Bugga et al., 1998). Because the LIF-deficient mice have a less severe phenotype than the LIF receptor and gp130deficient mice, it is very likely that other LIF-like cytokines also play a role in inducing astrocyte differentiation. Other cytokines that would bind to LIF receptors, such as CNTF, oncostatin M, and interleukin-11, mimic the effects of LIF in inducing astrocyte differentiation from stem cells in vitro (Johe et al., 1996; Bonni et al., 1997; Murphy et al., 1997; Halfter et al., 1998; Mi and Barres, 1999; Yanagisawa et al., 2000). In addition, bone morphogenetic proteins have astrocyte-inducing activity by themselves (Gross et al., 1996; Rajan and McKay, 1998) and have been shown recently to synergize with LIF to induce astrocyte differentiation in vitro (Nakashima et al., 1999a).

Our results suggest that endothelial cells are a primary source of the LIF that promotes astrocyte differentiation. LIF expression has been observed previously in some adult endothelial cells (Grosset et al., 1995). Endothelial cells from different types of blood vessels are increasingly recognized as heterogeneous (H. U. Wang et al., 1998); thus, it is possible that they may differ in LIF expression as well. Our studies involved primarily capillary endothelial cells, and it is not clear whether endothelial cells from larger blood vessels would be capable of inducing astrocyte generation. Astrocytes, however, only ensheathe capillaries and small arterioles in the brain and not larger blood vessels (Peters et al., 1991). In the adult brain, LIF mRNA has been investigated previously by in situ hybridization and detected in some neurons (Lemke et al., 1996), as well as in reactive astrocytes after injury (Banner et al., 1997). We observed a low level of LIF mRNA in astrocyte lineage cells by RT-PCR. However, it is unlikely that they make any significant amount of LIF protein, because APCs do not induce their own differentiation when cultured at high density (Mi and Barres, 1999). Thus, the small LIF signal detected probably originates from the $5 \%$ of astrocytes present in our purified APC preparations (see Materials and Methods).

In addition to LIF, a number of other signals have been shown recently to promote astrocyte differentiation from stem cells in culture, although it is not clear yet whether they also normally play a role in vivo. Our findings also indicate that it is likely that other signals exist within the developing optic nerve that help to promote astrocyte differentiation For instance, although LIF neutralization primarily blocked the ability of endothelial cells to induce astrocyte differentiation in vitro, we found that astrocyte differentiation proceeds normally in transgenic mice deficient in LIF. Interestingly, recent studies indicate that LIF-related signals normally do play a role in promoting astrocyte differentiation within the rodent optic nerve, because there is a severe impairment of astrocyte differentiation within the optic nerves of transgenic mice that lack LIF receptors (M. Sendtner, personal communication). Our finding that pial cells produce some LIF mRNA but do not promote astrocyte differentiation also points to the existence of other signals, most likely made by endothelial cells, that help to promote astrocyte differentiation. For instance, endothelial cells might secrete bone morphogenetic proteins or produce Notch ligands (Wang and Barres, 2000). Notch signaling strongly promotes glial differentiation (Wang and Barres, 2000), and high levels of the Notch ligand jagged 1 are expressed by developing endothelial cells in the brain (Irvin et al., 1998). Thus, it is possible that endothelial cells promote astrocyte differentiation by both contact-mediated and soluble signaling mechanisms.

\section{How is the blood-brain barrier constructed?}

Our results suggest the possibility of a sequential series of interactions between endothelial and astrocyte lineage cells that progressively generate the adult blood-brain barrier. In the E17 optic nerve, astrocyte precursor cells are the primary cell type. This suggests that APCs probably induce the development of endothelium. VEGF, an endothelial mitogen, plays a crucial role in driving vasculogenesis (Folkman and D'Amore, 1996; Yancopoulos et al., 1998). Thus, APCs might express VEGF, which would drive parenchymal vasculogenesis and endothelial proliferation. These endothelial cells would then, in turn, drive the differentiation of APCs into astrocytes, as we have shown here. For instance, in the retina, blood vessels develop in close association with astrocytes, which secrete VEGF in response to local oxygen 
levels (Stone et al., 1995; Wechsler-Reya and Barres, 1997). Next, astrocyte differentiation could in turn trigger the formation of the blood-brain barrier (Rubin and Staddon, 1999) and pericyte development, which we have found occurs early postnatally within the optic nerve (data not shown; Folkman and D'Amore, 1996; Benjamin et al., 1998). Although it has long been proposed that astrocytes trigger the formation of the blood-brain barrier by inducing the formation of tight junctions between endothelial cells within the brain, convincing proof has been difficult to obtain (Rubin and Staddon, 1999). Our ability to purify and culture endothelial cells, as well as astrocytes and their precursor cells, should provide an excellent preparation with which to address some of these questions in the future.

\section{REFERENCES}

Banner LR, Moayeri N, Patterson PH (1997) LIF is expressed by astrocytes following cortical brain injury. Exp Neurol 147:1-9.

Barres BA (1999) A new role for glia: generation of neurons! Cell 97:667-670.

Barres BA, Hart IK, Coles HS, Burne JF, Voyvodic JT, Richardson WD, Raff MC (1992) Cell death and control of cell survival in the oligodendrocyte lineage. Cell 70:31-46.

Benjamin LE, Hemo I, Keshet E (1998) A plasticity window for blood vessel remodelling is defined by pericyte coverage of the preformed endothelial network and is regulated by PDGF-B and VEGF. Development 125:1591-1598.

Bonni A, Sun Y, Nadal-Vicens M, Bhatt A, Frank DA, Rozovsky I, Stahl N, Yancopoulos GD, Greenberg ME (1997) Regulation of gliogenesis in the central nervous system by the JAK-STAT signaling pathway. Science 278:477-483.

Bottstein J, Sato G (1979) Growth of a rat neuroblastoma cell line in serum-free supplemented medium. Proc Natl Acad Sci USA 76:514517.

Bugga L, Gadient RA, Kwan K, Stewart CL, Patterson PH (1998) Analysis of neuronal and glial phenotypes in brains of mice deficient in LIF. J Neurobiol 36:509-524.

Davis AA, Temple S (1994) A self renewing multipotential stem cell in the embryonic rat cerebral cortex. Nature 372:263-266.

Fok-Seang J, Miller RH (1992) Astrocyte precursors in neonatal rat spinal cord cultures. J Neurosci 12:2751-2764.

Folkman J, D'Amore P (1996) Blood vessel formation: what is its molecular basis? Cell 87:1153-1155.

Galli R, Pagano SF, Gritti A, Vescovi AL (2000) Regulation of neuronal differentiation in human CNS stem cell progeny by leukemia inhibitory factor. Dev Neurosci 22:86-95.

Goldman JE (1996) Developmental origins of astrocytes. In: Glial cell development (Jessen KR, Richardson WD, eds), p 31. Oxford: BIOS Scientific.

Gross RE, Mehler MF, Mabie PC, Zang Z, Santschi L, Kessler JA (1996) Bone morphogenetic proteins promote astroglial lineage commitment by mammalian subventricular zone progenitor cells. Neuron 17:595-606.

Grosset C, Jazwiec B, Taupin JL, Liu H, Richard S, Mahon F, Reiffers J, Moreau J, Ripoche J (1995) Biosynthesis of LIF by human endothelial cells. Blood 86:3763-3770.

Halfter H, Lotfi R, Westermann R, Young P, Ringelstein EB, Stogbauer FT (1998) Inhibition of growth and induction of differentiation of glioma cell lines by oncostatin M. Growth Factors 15:135-147.

Hatzopoulos AK, Folkman J, Vasile E, Eiselen GK, Rosenberg RD (1998) Isolation and characterization of endothelial progenitor cells from mouse embryos. Development 125:1457-1468.

Hughes SM, Lillien LE, Raff MC, Rohrer H, Sendtner M (1988) Ciliary neurotrophic factor induces type-2 astrocyte differentiation in culture. Nature 335:70-73.

Irvin D, Zurcher S, Nguyen T, Al-Samari T, Kornblum H (1998) Expression of jagged 1 and jagged 2 in postnatal rat brain. Soc Neurosci Abstr 24:1277.

Johe KK, Hazel TG, Muller T, Dugich-Djordjevic MM, McKay RD (1996) Single factors direct the differentiation of stem cells from the fetal and adult central nervous system. Genes Dev 10:3129-3140.

Koblar SA, Turnley AM, Classon BJ, Reid KL, Ware CB, Cheema SS, Murphy M, Bartlett PF (1998) Neural precursor differentiation into astrocytes requires signaling through the leukemia inhibitory factor receptor. Proc Natl Acad Sci USA 95:3178-3181.

Laitinen L (1987) Griffonia simplicifolia lectins bind specifically to endothelial cells and some epithelial cells in mouse tissues. Histochem J 19:225-234.

Lemke R, Gadient RA, Schliebs R, Bigl V, Patterson PH (1996) Neuronal expression of LIF in the rat brain. Neurosci Lett 215:205-208.
Levison SW, Goldman JE (1993) Both oligodendrocytes and astrocytes develop from progenitors in the subventricular zone of postnatal rat forebrain. Neuron 10:201-212.

Lillien LE, Sendtner M, Rohrer H, Hughes SM, Raff MC (1988) Type-2 astrocyte development in rat brain cultures is initiated by a CNTF-like protein produced by type-1 astrocytes. Neuron 1:485-494.

Marin-Padilla M (1995) Prenatal development of fibrous (white matter), protoplasmic (gray matter), and layer I astrocytes in the human cerebral cortex: a Golgi study. J Comp Neurol 357:554-572.

Mi H, Barres BA (1999) Purification and characterization of astrocyte precursor cells in the developing rat optic nerve. J Neurosci 19:1049-1061.

Miller RH, Williams BP, Cohen J, Raff MC (1984) A4: an antigenic marker of neural tube-derived cells. J Neurocytol 13:329-338.

Miller RH, David S, Patel R, Abney ER, Raff MC (1985) A quantitative immunohistochemical study of macroglial cell development in the rat optic nerve: in vivo evidence for two distinct glial lineages. Dev Biol 111:35-41.

Miller RH, ffrench-Constant C, Raff MC (1989) The macroglial cells of the rat optic nerve. Annu Rev Neurosci 12:517-534.

Minamikawa T, Miyake T, Takamatsu T, Fujita S (1987) A new method of lectin histochemistry for the study of brain angiogenesis. Histochemistry 87:317-320.

Murphy M, Dutton R, Koblar S, Cheema S, Bartlett P (1997) Cytokines which signal through the LIF receptor and their actions in the nervous system. Prog Neurobiol 52:355-378.

Nakagaito Y, Yoshida T, Satoh M, Takeuchi M (1995) Effects of LIF on the differentiation of astrocyte progenitor cells from embryonic mouse cerebral hemispheres. Brain Res Dev Brain Res 87:220-223.

Nakashima K, Yanagisawa M, Arakawa H, Kimura N, Hisatune T, Kawabata M, Miyazono K, Taga T (1999a) Synergistic signaling in fetal brain by STAT3-Smad1 complex bridged by p300. Science 284:479-482.

Nakashima K, Wiese S, Yanagisawa M, Arakawa H, Kimura N, Hisatsune T, Yoshida K, Kishimoto T, Sendtner M, Taga T (1999b) Developmental requirement of gp130 signaling in neuronal survival and astrocyte differentiation. J Neurosci 19:5429-5434.

Newman PJ (1997) The biology of PECAM-1. J Clin Invest [Suppl 11] 100:S25-S29.

Penfield W (1932) Cytology and cellular pathology of the nervous system. New York: Hoeber.

Peters A, Palay SL, Webster HF (1991) The fine structure of the nervous system. New York: Oxford UP.

Qian X, Davis AA, Goderie SK, Temple S (1997) FGF2 concentration regulates the generation of neurons and glia from multipotent cortical stem cells. Neuron 18:81-93.

Qian X, Goderie SK, Shen Q, Stern JH, Temple S (1998) Intrinsic programs of patterned cell lineages in isolated vertebrate CNS ventricular zone cells. Development 125:3143-3152.

Raff MC (1989) Glial cell diversification in the rat optic nerve. Science 243:1450-1455.

Raff MC, Miller RH, Noble M (1983) A glial progenitor cell that develops in vitro into an astrocyte or an oligodendrocyte depending on culture medium. Nature 303:390-396.

Raff MC, Abney ER, Miller RH (1984) Two glial cell lineages diverge prenatally in rat optic nerve. Dev Biol 106:53-60.

Rajan P, McKay RD (1998) Multiple routes to astrocytic differentiation in the CNS. J Neurosci 18:3620-3629.

Richards LJ, Kilpatrick TJ, Dutton R, Tan SS, Gearing DP, Bartlett PF, Murphy M (1996) LIF or related factors promote the differentiation of neuronal and astrocytic precursors within the developing murine spinal cord. Eur J Neurosci 8:291-299.

Rubin LL, Staddon JM (1999) The cell biology of the blood-brain barrier. Annu Rev Neurosci 22:11-28.

Stockli KA, Lillien LE, Naher-Noe M, Breitfeld G, Hughes RA, Raff MC, Thoenen H, Sendtner M (1991) Regional distribution, developmental changes, and cellular localization of CNTF mRNA and protein in the rat brain. J Cell Biol 115:447-459.

Stone J, Itin A, Alon T, Pe'er J, Gnessin H, Chan-Ling T, Keshet E (1995) Development of retinal vasculature is mediated by hypoxiainduced vascular endothelial growth factor expression by neuroglia. J Neurosci 15:4738-4747.

Suarez I, Raff MC (1989) Subpial and perivascular astrocytes associated with nodes of Ranvier in the rat optic nerve. J Neurocytol 18:577-582.

Tontsch U, Bauer HC (1989) Isolation, characterization, and long-term cultivation of porcine and murine cerebral capillary endothelial cells. Microvasc Res 37:148-161.

Wang HU, Chen ZF, Anderson DA (1998) Molecular distinction and angiogenic interactions between embryonic arteries and veins revealed by ephrin-B2 and its receptor Eph-B4. Cell 93:741-753.

Wang S, Barres BA (2000) Up a notch: instructing gliogenesis. Neuron 27:197-200. 
Ware CB, Horowitz MC, Renshaw BR, Hunt JS, Davison BL, Gearing DP (1995) Targeted disruption of the low-affinity LIF receptor gene causes placental, skeletal, neural and metabolic defects and results in perinatal death. Development 121:1283-1299.

Wechsler-Reya R, Barres BA (1997) Retinal development: communication helps you see the light. Curr Biol 7:R433-R436.

Yanagisawa M, Nakashima K, Arakawa H, Ikenak K, Yoshida K, Kishimoto T, Hisatsune T, Taga T (2000) Astrocyte differentiation of fetal neuroepithelial cells by interleukin-11 via activation of a common cytokine signal transducer gp130 and a transcription factor STAT3. J Neurochem 74:1498-1504.

Yancopoulos G, Klagsbrun M, Folkman J (1998) Vaculogenesis, angio- genesis, and growth factors: ephrins enter the fray at the border. Cell 93:661-664.

Yoshida T, Satoh M, Nakagaito Y, Kuno H, Takeuchi M (1993) Cytokines affecting survival and differentiation of an astrocyte progenitor cell lines. Brain Res Dev Brain Res 76:147-150.

Zerlin M, Goldman JE (1997) Interactions between glial progenitors and blood vessels during early postnatal corticogenesis: blood vessel contact represents an early stage of astrocyte differentiation. J Comp Neurol 387:537-546.

Zerlin M, Levison SW, Goldman JE (1995) Early patterns of migration, morphogenesis, and intermediate filament expression of subventricular zone cells in the postnatal rat forebrain. J Neurosci 15:7238-7249. 